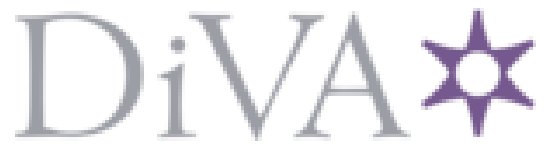

http://www.diva-portal.org

Preprint

This is the submitted version of a paper presented at 2nd IFIP International Internet of Things (IoT) Conference, 31 October - 1 November 2019, Tampa, FL, USA.

Citation for the original published paper:

Mähler, V. (2020)

The Thing About the Internet of Things: Scoping the Social Science Discourse in IoT Research

In: Casaca A., Katkoori S., Ray S., Strous L. (ed.), Internet of Things: A Confluence of Many Disciplines (pp. 235-251). Springer

IFIP Advances in Information and Communication Technology

https://doi.org/10.1007/978-3-030-43605-6_14

N.B. When citing this work, cite the original published paper.

Permanent link to this version:

http://urn.kb.se/resolve?urn=urn:nbn:se:umu:diva-175302 


\title{
The thing about the Internet of Things: Scoping the Social Science discourse in IoT research
}

\author{
Viktor Mähler [0000-0001-7267-2066] \\ ${ }^{1}$ Department of Informatics, Umeå University, 90187 Umeå, Sweden \\ viktor.mahler@umu.se
}

\begin{abstract}
Internet of Things (IoT) is predicted to change not only industry, businesses and commerce, but also our everyday lives. Social science research surrounding IoT is important and necessary because of this predicted change. In this 'scoping study' keyword-clusters are being used to identify key-concepts within the social science subject area, giving an overview of the scopes within said concepts, and where social science stands to benefit from further research. The result is the thematization of 25 keywords, spread within 5 clusters; Organization, Logistics, Infrastructure, Technology and Protection. This paper argues that more research is needed in human-centric aspects, and that in doing this - a potential sixth theme regarding ethics can emerge where the subject field of social science can stand to generate a larger impact on IoT research.
\end{abstract}

Keywords: Internet of Things, Scoping Study, Themes, Social Science, Ethics.

\section{Introduction.}

Internet of Things is a buzzword. Not in the negative sense, but rather in the everybodyis-talking-about-it sense, as evident by the conferences, special editions and symposiums that are springing up all around the globe in regards to this phenomenon.

The interest in IoT show no indication of stopping in the foreseeable future and estimations predict that in 2020 there will be 30 billion connected devices worldwide and that the value surrounding IoT will reach up to 1.3 trillion dollars (Statista, 2019; Ericsson, 2016). If these estimations prove correct then IoT will truly change the modern landscape as we know it, and IoT research have already rapidly transcended the scope or concept of a single field of research. Today IoT is influencing both governmental and private sectors, transport, e-health, customer behavior, manufacturing, privacy and the very cities that we live in (Porter \& Heppelmann, 2014).

These areas are all aspects within the social sciences, each with their own research traditions and methodologies, which will need to be able to work together and conduct research alongside one another in order to contribute to the body of knowledge. This knowledge then serves to inform researchers, decision-makers as well as social science undergraduates and graduates that will eventually play a role in $e . g$ policymaking and politics - affecting the lives of many, for good or bad (Tarschys \& Lachapelle, 2010). 
Most of the IoT research that is being performed today concerns technological advancements and incremental improvements on sensors and hardware. Examining publications indexed by the research database Scopus, the subject-fields of Engineering and Computer Science are currently over-represented within the database when searching for "IoT" or "Internet of Things" (as shown in the literature selection).

The field of information systems research has already studied and showcased the need for co-operation and involvement of employees to facilitate adoption of IT within organizations (Gallivan et al., 2005; Botta-Genoulaz \& Millet, 2006). And while individuals previously have had the ability to opt-out of connectivity and technology outside of work, the massive implications of IoT can shift that ability on a societal level. Technological adoption on such a massive scale, as for instance a city, is a new phenomenon - one where the focus now risks being on the technology of the smart city, rather than the inhabitants within. Because of this the social science subject-area was selected for this scoping study, in order to understand key concepts within, provide an overview for researchers and practitioners, and to make suggestions for future research.

The research question that this scoping study aims to answer is; "What areas are being addressed within the social science subject-field of IoT-literature in research journals and where can further social science research stand to contribute?",

Through the analysis of 8290 keywords, and a selective reading of peer-reviewed journal articles, the scopes for different key concepts within IoT research is presented and thematized. The primary aim for this study is to explore how IoT is addressed within Social Science literature, to examine key concepts that are discussed and also to present an argument for strengthening inter-disciplinary co-operation within Social Sciences. Based on the analysis and results from the scoping study, an additional argument is made for the need of further research in social science concerning humancentric aspects and ethics. This study concludes that five themes can be observed in terms of IoT in social science, and that a sixth theme (ethics) has a potential to emerge. The study identified a lack in human-centric and ethics research, and argue that such research could prove beneficial to the field. The implications, should the Social Sciences fail to establish themselves within the human-centric aspects of IoT discourse, is that adaptions and implementations of IoT risks being left to the devices of individuals or organizations with the intent of monetizing personal data generated by users, selling user information and infringing on the privacy of millions.

\section{Research methodology.}

A scoping study, as described by Arksey \& O’Malley (2015) focuses towards quickly mapping key concepts within a research area, mapping the main sources as well as providing a comprehensive study - where the depth of the study can vary depending on the review. This type of study can also function in terms of deciding whether or not the undertaking of a full systematic literature review would be valuable, summarizing research findings and identifying gaps in the literature (ibid.).

This research methodology was selected because of its aim to give an overarching view of research within a field - which fit well with the research question at hand. 
The subject field of Social Science was the main interest, and in order to get as wide of a selection among research journals, no exclusions were made on journals within the selected subject field. This scoping study focuses on breadth in terms of literature selection in order to showcase key concepts and adhere to the aspect of 'relevance' rather than the 'rigor' of a full systematic literature review in terms of in-depth analysis (Senn, 1998).

Scopus was selected as the research database for this study. Scopus is a part of the Elsevier publishing company, and the largest abstract and citation database of peerreviewed literature (Elsevier, 2019) being the reason for its selection.

In order to assist with the analysis and charting of the data, the software "VOSviewer" was used. VOSviewer is a tool used to construct as well as visualize bibliometric networks (Centre for Science and Technology Studies, 2018).

Using the VOSviewer-software a keyword map was created by examining the bibliographic data collected from 1489 articles - directing the study towards the cooccurrence of keywords relating to the chosen subject-fields within every published journal paper in the Scopus database. 8290 keywords were identified, where 25 were refined into five clusters detailing key concepts, and through analysis of these key concepts five themes emerged that were expanded upon and examined.

\subsection{Literature selection}

Scopus was selected as the reference database, and only journal articles were selected for the analysis. Delimitation of the scope to 'journals only' was made in order to assure reputable outlets, and to condense keywords grown out of rigorous research, compared to the lesser rigor associated with conference proceedings in some subject fields. In order to capture as many facets as possible, articles were selected from the subject-areas of; Social Science, Business, Management and Accounting, Psychology as well as Arts and Humanities - within Scopus own preassigned subject-area search options.

The reason for including Psychology and Arts and Humanities into the subject-area was to capture eventual cross-disciplinary publications, such as Human-Computer Interaction or otherwise related areas. Engineering and computer science journals were not excluded from the search, provided that the article itself was in relation to the subject area of Social Sciences. This was done in order to expand the scope of the search and to get an idea of where the social scientific discourse is being held.

In order to look at the most recent research, it was decided that publications should be no older than 2014, to capture the trend of the last five years. In order to see the current trend being discussed, as well as the areas of focus within the body of knowledge, the following search string was generated:

( TITLE-ABS-KEY ( iot ) OR TITLE-ABS-KEY ("Internet of Things" ) ) AND PUBYEAR > 2013 AND PUBYEAR $<2020$ AND ( LIMIT-TO ( SUBJAREA, "SOCI" ) OR LIMIT-TO ( SUBJAREA, "BUSI" ) OR LIMIT-TO ( SUBJAREA, "ARTS" ) OR LIMIT-TO ( SUBJAREA, "PSYC" ) ) AND ( LIMIT-TO ( DOCTYPE, "ar" ) ) AND ( LIMIT-TO ( LANGUAGE, "English" ) ) 
The final search was performed 20/6 -2019 and the criteria yielded 1489 articles, where 786 were from Social Sciences, 730 from Business, Management and Accounting, 85 from psychology and 84 from Arts and Humanities. The discrepancy when looking at the number of articles (1489) and the number of articles when adding up the aforementioned subject areas (1685) could be explained by some articles being in multiple differing categories. The selection for this scoping study is described in the flowchart below, with the decision of which items to keep and remove, respectively.

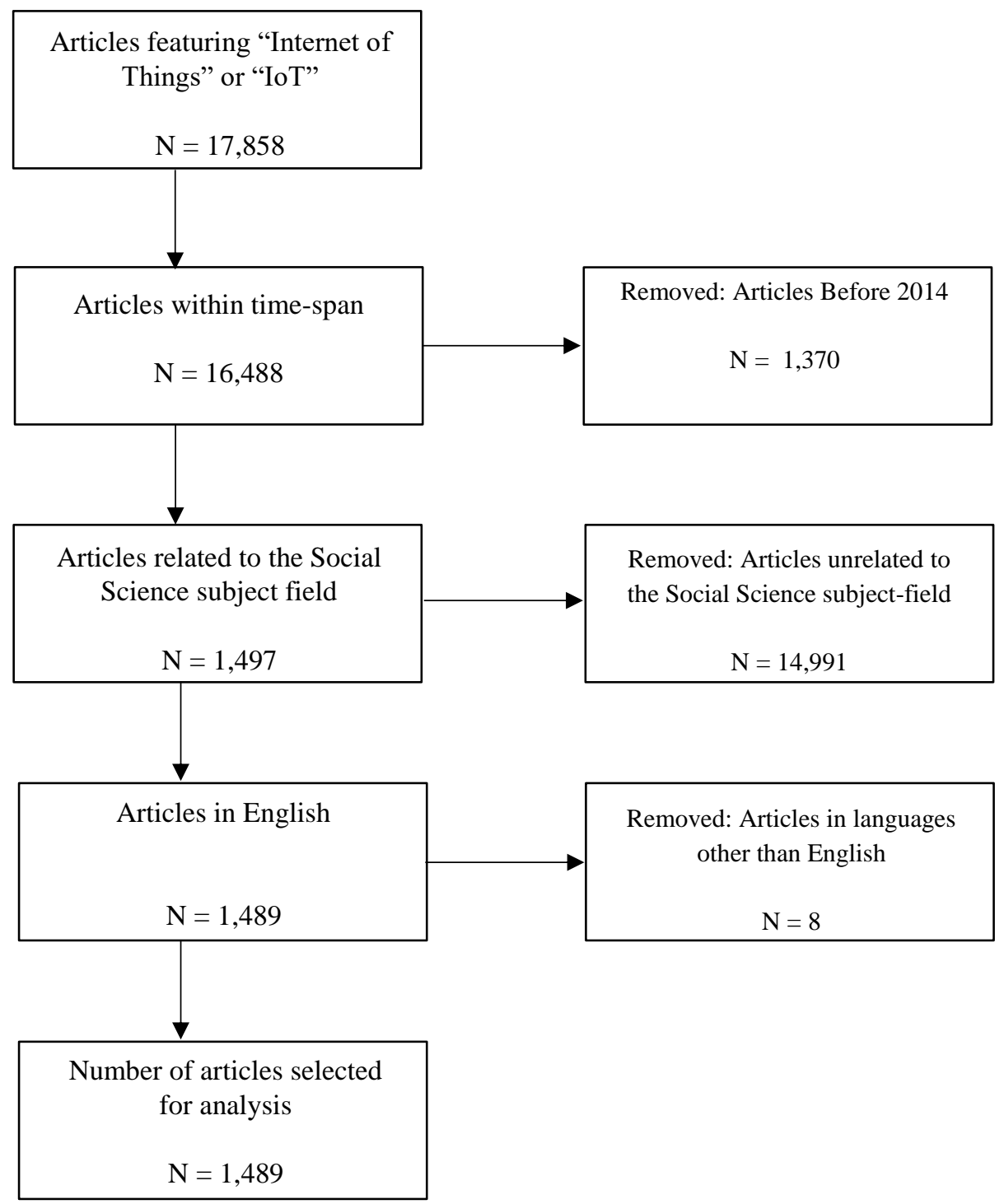

Figure 1. Flowchart of literature selection process. 


\subsection{Literature analysis}

The total number of available keywords was 8290 . Keywords that appeared in at least 29 different articles were selected to be part of the study, leaving 34 keywords in total. Keyword duplicates were removed (e.g "Smart City" and "Smart Cities") where the word with the lowest scoring link strength was the one that were removed. Keywords such as "Internet of Things", "IoT" and variations thereof were also removed, leaving a total of 25 keywords remaining, split into five different clusters that can be observed as differentiated by colors. In regards to "Privacy", "Data Privacy", "Security" and "Network Security", they were chosen to remain separated; due to each keyword having different implications in the literature. The strength of the connection between the keywords is visualized in differing boldness of the lines connecting each of the keywords.

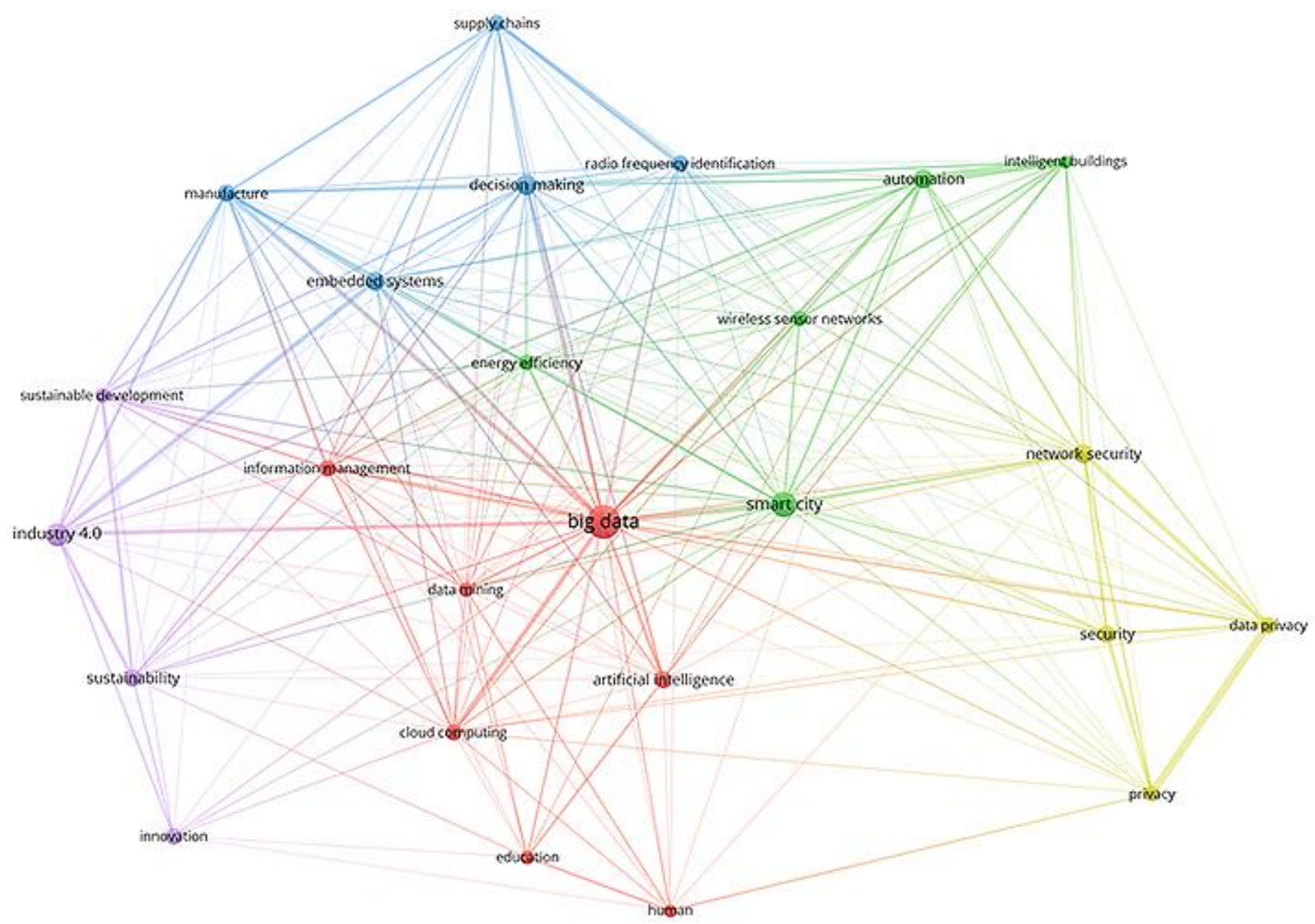

Figure 2. The 25 Most common keywords out of 8290 available, divided into 5 clusters. 
Based on the keywords produced by the literature analysis, each cluster was examined and a select reading of the most cited articles for each keyword was performed.

In order to summarize the keyword-clusters into Themes the related articles were analyzed in terms of what topic they covered and their connection to each other. What Arksey \& O'Malley (2015) describes as 'key concepts' was identified within each cluster, and the theme emerged from the identified concept. Heavily cited articles were generally premiered over lesser cited - unless the article could be considered to be related to a specific scope within the theme.

When articles were selected for the inclusion to describe the scope of a particular theme, the search included the same keyword duplicates that previously had been separated from the analysis. This was made in order to increase the breadth of the search without straying from the examination of associated scopes. An example of this would be that the search string included "Smart City OR Smart Cities" or "RFID OR Radio Frequency Identification".

\section{Results.}

The scoping study resulted in 1489 articles being chosen for deeper analysis. 25 keywords emerged, and were split into five different clusters, presented in section 3.1. The clusters were used to formulate themes through the reviewing of literature connected to each keyword, and its theme. This allowed for a scoping of the literature within each theme leading up to the selection and addition of articles deemed to fit within that particular theme, guiding towards future research.

The themes are described and expanded upon in section 3.2 where an analysis regarding the connections between keywords is presented alongside a summary of the scope of for each theme.

\subsection{Keywords within the Social Science subject-field literature}

The Keywords for each theme are displayed firstly, along with a corresponding $I D$ for each Keyword.

The Theme is the overall area of concern that deals with the Keywords, and their link to one another, making them a cluster. Each theme is colored differently from the other which was done in order to make them easier to identify from one another.

The Occurrence is how many times Keywords are mentioned in the published journals - and they are presented in descending order of strength for each Theme.

\begin{tabular}{|l|c|l|c|}
\hline KEYWORD: & ID: & THEME: & OCCURRENCE: \\
\hline Industry 4.0 & A-1 & Organization & 65 \\
\hline Sustainability & A-2 & Organization & 43 \\
\hline Innovation & A-3 & Organization & 40 \\
\hline Sustainable Development & A-4 & Organization & 34 \\
\hline
\end{tabular}




\begin{tabular}{|l|c|c|c|}
\hline KEYWORD (Continued.): & ID: & THEME: & OCCURRENCE: \\
\hline Decision Making & B-1 & Logistics & 54 \\
\hline Embedded Systems & B-2 & Logistics & 50 \\
\hline Manufacture & B-3 & Logistics & 41 \\
\hline Radio Frequency Identification & B-4 & Logistics & 39 \\
\hline Supply Chains & B-5 & Logistics & 36 \\
\hline Smart City & C-1 & Infrastructure & 77 \\
\hline Automation & C-2 & Infrastructure & 49 \\
\hline Energy Efficiency & C-3 & Infrastructure & 36 \\
\hline Wireless Sensor Networks & C-4 & Infrastructure & 36 \\
\hline Intelligent Buildings & C-5 & Infrastructure & 29 \\
\hline Big Data & D-1 & Technology & 121 \\
\hline Artificial Intelligence & D-2 & Technology & 43 \\
\hline Cloud Computing & D-3 & Technology & 40 \\
\hline Information Management & D-4 & Technology & 39 \\
\hline Data Mining & D-5 & Technology & 34 \\
\hline Education & D-6 & Technology & 30 \\
\hline Human & D-7 & Technology & 29 \\
\hline Network Security & E-1 & Protection & 48 \\
\hline Security & E-2 & Protection & 44 \\
\hline Data Privacy & E-3 & Protection & 39 \\
\hline Privacy & E-4 & Protection & 37 \\
\hline
\end{tabular}

Table 1. Keywords, Their ID, Theme of Cluster and Keyword Occurrence.

\subsection{Themes based on keywords from the Social Science subject-field litterature analysis}

The articles related to each theme has been chosen in order to provide an understanding of different aspects within the scope of the theme, in which journals they are being addressed and the number of citations, according to the Scopus database for each article (Which has been abbreviated as \#C in the tables below).

Each theme will be presented, with their respective table color-coded to correspond with the themes in the keyword section (3.1). The scope of the theme itself will also be laid out, based on selected reading. It should be noted that while the themes have been isolated based on the clustered keywords, it does not mean that the themes are isolated from each other - where e.g the keyword big data plays a part in every theme.

Certain themes have stronger links towards each other than others, and will therefore overlap one another. Noteworthy keyword connections (or lack-there-of) identified in VOSviewer will be also be presented, and later discussed.

The table of articles for each theme will feature articles presented in order of descending citations, however they should be considered of equal importance, functioning as scope overview for further reading and referencing. Some articles within one theme may touch upon aspects within other themes, where it serves to highlight that the themes are not in isolation. 
Organization - The keywords for the organization theme was identified as; Industry 4.0, Sustainability, Innovation and Sustainable Management. The theme revolves around IoTs role on industrial aspects and future improvement within an organizational or production-oriented setting. The following articles have been chosen to highlight the different scopes of the Organization theme:

\begin{tabular}{|l|l|l|c|}
\hline ARTICLE: & AUTHOR(S): & JOURNAL, YEAR: & \#C: \\
\hline $\begin{array}{l}\text { The Internet of Things (IoT): } \\
\text { Applications, investments, } \\
\text { and challenges for enterprises }\end{array}$ & Lee, I., Lee, K. & Business Horizons, 2015 & 349 \\
\hline $\begin{array}{l}\text { Business models for the } \\
\text { Internet of Things }\end{array}$ & $\begin{array}{l}\text { Dijkman, R.M., Sprenkels, B., } \\
\text { Peeters, T., Janssen, A. }\end{array}$ & $\begin{array}{l}\text { International Journal of } \\
\text { Information Management, } \\
2015\end{array}$ & 109 \\
\hline $\begin{array}{l}\text { A Complex View of Industry } \\
4.0\end{array}$ & $\begin{array}{l}\text { Roblek, V., Meško, M., } \\
\text { Krapež, A. }\end{array}$ & SAGE Open, 2016 & 86 \\
\hline $\begin{array}{l}\text { Industry 4.0: State of the art } \\
\text { and future trends }\end{array}$ & Xu, L.D., Xu, E.L., Li, L. & $\begin{array}{l}\text { International Journal of } \\
\text { Production Research, 2018 }\end{array}$ & 76 \\
\hline $\begin{array}{l}\text { Sustainable industrial value } \\
\text { creation: Benefits and } \\
\text { challenges of industry 4.0 }\end{array}$ & $\begin{array}{l}\text { Kiel, D., Müller, J.M., } \\
\text { Arnold, C., Voigt, K.-I. }\end{array}$ & $\begin{array}{l}\text { International Journal of } \\
\text { Innovation Management, } \\
2017\end{array}$ & 33 \\
\hline
\end{tabular}

Table 2. List of keyword ID, connected article, author(s), journal, year and number of citations for the "Organization" theme.

The keyword analysis from showcases that the most commonly occurring keyword industry 4.0 connects towards both the logistics, infrastructural and technical themes. Notably in the Protection theme; industry 4.0 connected to network security but not to any of the keywords relating to privacy or data privacy. This does not mean that privacy was a non-issue, but in terms of the Protection theme, the network security was of greater interest within the Organization theme. Unsurprisingly there was also strong connection between industry 4.0 and the keywords manufacture and embedded systems within the Logistics theme. The keyword innovation was one of the few keywords that connected to both human and education, albeit weakly.

The scope of the Organization theme primarily focuses on the business aspect of IoT, where it is examined the extent to which production can be improved upon (Roblek et al., 2016), which way IoT will change the way that businesses operate (Dijkman et al., 2015; Kiel et al., 2017), and wherein monetary value will present itself and how to utilize sensor-based technology (Lee \& Lee, 2015; Xu et al., 2018). The surveyed articles reveals a generally positive outlook on what IoT will come to entail - and many articles theorize about a considerable growth of revenue, but of course challenges are also presented, but these mainly relate towards technology and sustainability. Less reflections in terms of Organizations are related to the change IoT will mean for workers within the industry - and changing aspects of their work, whereas change for customers is covered in a wider sense.

Discussed challenges within the Organization theme-literature relate to data storage, disruptive changes to business models and emergence of new business eco-systems and how these can be utilized. Opportunities that are being discussed within the literature revolve around monetary gains, optimizing production and maintenance as well as the benefits towards customers. 
Logistics - Keywords related to the Logistics theme were; Decision Making, Embedded Systems, Manufacture, Radio Frequency Identification and Supply Chains. The logistics theme focuses on IoTs impact on transportation, production and overview of goods or machinery. The following articles have been chosen to highlight the different scopes of the Logistics theme:

\begin{tabular}{|l|l|l|c|}
\hline ARTICLE: & AUTHOR(S): & JOURNAL, YEAR: & \#C: \\
\hline $\begin{array}{l}\text { Smart manufacturing: Past } \\
\text { research, present findings, and } \\
\text { future directions }\end{array}$ & $\begin{array}{l}\text { Kang, H.S., Lee, J.Y., Choi, } \\
\text { S., Kim, H., Park, J.H., Son, } \\
\text { J.Y., Kim, B.H., Noh, S.D }\end{array}$ & $\begin{array}{l}\text { International Journal of } \\
\text { Precision Engineering and } \\
\text { Manufacturing - Green } \\
\text { Technology, 2016 }\end{array}$ & 203 \\
\hline The Future of Retailing & $\begin{array}{l}\text { Grewal, D., Roggeveen, } \\
\text { A.L., Nordfält, J. }\end{array}$ & Journal of Retailing, 2017 & 91 \\
\hline Smart manufacturing & Kusiak, A. & $\begin{array}{l}\text { International Journal of } \\
\text { Production Research, 2018 }\end{array}$ & 76 \\
\hline $\begin{array}{l}\text { ICT in multimodal transport and } \\
\text { technological trends: Unleashing } \\
\text { potential for the future }\end{array}$ & $\begin{array}{l}\text { Harris, I., Wang, Y., Wang, } \\
\text { H. }\end{array}$ & $\begin{array}{l}\text { International Journal of } \\
\text { Production Economics, } \\
\text { 2015 }\end{array}$ & 61 \\
\hline $\begin{array}{l}\text { Bottom-up approach based on } \\
\text { Internet of Things for order } \\
\text { fulfillment in a collaborative } \\
\text { warehousing environment }\end{array}$ & $\begin{array}{l}\text { Reaidy, P.J., Gunasekaran, } \\
\text { A., Spalanzani, A. }\end{array}$ & $\begin{array}{l}\text { International Journal of } \\
\text { Production Economics, } \\
\text { 2015 }\end{array}$ & 49 \\
\hline
\end{tabular}

Table 3. List of keyword ID, connected article, author(s), journal, year and number of citations for the "Logistics" theme.

The keyword analysis show that decision making is the most commonly occurring keyword for this theme, where it connects to many of the other themes except for innovation in the Organization theme, and education in the Technology theme.

The keyword supply chains, despite having a low occurrence were connected towards all themes, but radio frequency identification had no connections towards the Organizational theme, showing that it was less frequently occurring, even in relation to industry 4.0 - where the connection instead were towards embedded systems. In this theme decision making has a strong connection towards every other keyword within the theme and the other major keyword within the other themes as well.

The scope of the logistics theme deals with IoT within transportation, production, factories and the equipment within them. RFID is an important aspect of this theme, and research explores the introduction and implementation of embedded systems (Reaidy et al., 2015) and freighting/shipping (Harris et al., 2015). The keyword decision making and its facilitation (Grewal et al., 2017; Harris et al., 2015) remains a central aspect throughout this theme, as well as effects on retail in relation to transportation, delivering and storing. Another aspect that is prevalent in the Logistics theme is that of Smart Manufacturing and Smart Factories (Kang et al., 2016; Kusiak, 2018) - and how IoT will come to affect the modes of production and machines.

Discussed challenges within the Logistics theme literature includes utilization of Big Data in terms of simplifying supply-chains, the technological transition towards smart manufacturing and expected consumer effect. Opportunities that were discussed within the Logistics literature were productivity increases, easier cargo tracking, increased revenue streams in retail and manufacturing. 
Infrastructure - The keywords identified for the infrastructure theme was; Smart City, Automation, Energy Efficiency, Wireless Sensor Networks and Intelligent Buildings. The Infrastructure theme deals with the improvements IoT can have in terms of public services, tourism, energy, cities and networks. The following articles have been chosen to highlight the different scopes of the Infrastructure theme:

\begin{tabular}{|l|l|l|c|}
\hline ARTICLE: & AUTHOR(S): & JOURNAL, YEAR: & \#C: \\
\hline $\begin{array}{l}\text { Smart tourism: foundations and } \\
\text { developments }\end{array}$ & $\begin{array}{l}\text { Gretzel, U., Sigala, M., } \\
\text { Xiang, Z., Koo, C. }\end{array}$ & Electronic Markets, 2015 & 217 \\
\hline The role of big data in smart city & $\begin{array}{l}\text { Hashem, I.A.T., Chang, } \\
\text { V., Anuar, N.B., Adewole, } \\
\text { K., Yaqoob, I., Gani, A., } \\
\text { Ahmed, E., Chiroma, H.c }\end{array}$ & $\begin{array}{l}\text { International Journal of } \\
\text { Information Management, } \\
2016\end{array}$ & 170 \\
\hline $\begin{array}{l}\text { Urban computing in the wild: A survey } \\
\text { on large scale participation and citizen } \\
\text { engagement [...] }\end{array}$ & Salim, F., Haque, U. & $\begin{array}{l}\text { International Journal of } \\
\text { Human Computer Studies, } \\
\text { 2015 }\end{array}$ & 40 \\
\hline $\begin{array}{l}\text { A Unified Smart City Model (USCM) } \\
\text { for smart city conceptualization and } \\
\text { benchmarking }\end{array}$ & $\begin{array}{l}\text { Anthopoulos, L., } \\
\text { Janssen, M., } \\
\text { Weerakkody, V. }\end{array}$ & $\begin{array}{l}\text { International Journal of } \\
\text { Electronic Government } \\
\text { Research, 2016 }\end{array}$ & 30 \\
\hline $\begin{array}{l}\text { Towards the next generation of } \\
\text { intelligent building: An assessment } \\
\text { study of current automation and future } \\
\text { IoT based systems [...] }\end{array}$ & $\begin{array}{l}\text { Lilis, G., Conus, G., } \\
\text { Asadi, N., Kayal, M. }\end{array}$ & $\begin{array}{l}\text { Sustainable Cities and } \\
\text { Society, 2017 }\end{array}$ & 25 \\
\hline
\end{tabular}

Table 4. List of keyword ID, connected article, author(s), journal, year and number of citations for the "Infrastructure" theme.

The keyword analysis show smart city as the most prominent keyword, where it connecting to every other keyword in every other theme with the notable exception of education and human. In this theme automation was also connected to every other theme with a strong connection towards embedded systems, smart city, intelligent buildings and big data. The Infrastructure theme also has a closer link towards the Protection theme than the other themes. The keyword energy efficiency connected to every other theme, however it did not connect to the keywords industry 4.0 or supply chains. The keyword of wireless sensor networks were most connected towards the Logistics theme, and the Technology theme, where it only had one connection to the Organization and Protection theme, being; industry 4.0 and network security.

The Scope of the Infrastructure theme deals in IoT within a cityscape, e-health, the energy management required and networks. Benefits towards tourism with the help of IoT implementations (Gretzel, 2015) were discussed and explored. Like the Logistics theme, transports and optimization of these were also of interest - however these transports relate to infrastructure such as waste management and tracking of service vehicles (Hashem et al., 2016) rather than cargo transportation. Models on how to design the smart city concept is explored (Anthopoulos et al., 2016), along with the design of intelligent buildings (Lilis, 2017). Another, smaller, scope was towards exploring the design of the smart city in terms of interaction (Salim \& Haque, 2015).

Discussed challenges within the Infrastructure theme were related towards the generation of big data, increased energy demands and digitalization of older buildings. Opportunities that are frequently discussed are; automation of services, increased city monitoring capabilities and the creation of eco-systems. 
Technology - Within the Technology theme the keywords that were found was; Big Data, Artificial Intelligence, Cloud Computing, Information Management, Data Mining, Education and Human. The technology theme deals with the IoT in relation to hardware, management of data, and technological advancements. This theme features a heavy focus towards "Big Data". The following articles have been chosen to highlight the different scopes of the Technology theme:

\begin{tabular}{|l|l|l|c|}
\hline ARTICLE: & AUTHOR(S): & JOURNAL, YEAR: & \#C: \\
\hline $\begin{array}{l}\text { Significance and Challenges of } \\
\text { Big Data Research }\end{array}$ & $\begin{array}{l}\text { Jin, X., Wah, B.W., Cheng, } \\
\text { X., Wang, Y. }\end{array}$ & Big Data Research, 2015 & 205 \\
\hline The role of big data in smart city & $\begin{array}{l}\text { Hashem, I.A.T., Chang, V., } \\
\text { Anuar, N.B., Adewole, K., } \\
\text { Yaqoob, I., Gani, A., Ahmed, } \\
\text { E., Chiroma, H.c }\end{array}$ & $\begin{array}{l}\text { International Journal of } \\
\text { Information Management, } \\
2016\end{array}$ & 170 \\
\hline $\begin{array}{l}\text { The Internet-of-Things: Review } \\
\text { and research directions }\end{array}$ & $\begin{array}{l}\text { Ng, I.C.L., Wakenshaw, } \\
\text { S.Y.L. }\end{array}$ & $\begin{array}{l}\text { International Journal of } \\
\text { Research in Marketing, 2017 }\end{array}$ & 56 \\
\hline $\begin{array}{l}\text { Conceptualizing and measuring } \\
\text { quality of experience of the } \\
\text { internet of things [...] }\end{array}$ & Shin, D.-H.. & $\begin{array}{l}\text { Information and } \\
\text { Management, 2017 }\end{array}$ & 39 \\
\hline $\begin{array}{l}\text { Putting things to work: Social } \\
\text { and policy challenges for the } \\
\text { Internet of things }\end{array}$ & Dutton, W.H. & Info, 2014 & 33 \\
\hline
\end{tabular}

Table 5. List of keyword ID, connected article, author(s), journal, year and number of citations for the "Technology" theme.

The keyword analysis showed big data to be the most prominent keyword, where it had a connection towards every other keyword. The keyword human surprisingly had the shared lowest occurrence out of all keywords - with only 29 occurrences (tied with intelligent buildings), and the weakest link strength to the other themes. The human keyword was mostly featured within the technology theme, only having one connection to the Organizational theme (innovation) and the Infrastructural theme (automation). In the Protection theme human was linked to network security and privacy and in the Logistics theme human was connected to decision making and radio frequency identification.

The scope of the theme proved difficult to portray, even if the theme itself became clear after analyzing the keywords. As described in the introduction of section 3.2, many areas have some overlap, and this especially noticeable in the Technology theme - where it becomes more of a reference category, as the 'hard sciences' of engineering and computer science were left out. The literature in terms of the technological aspect revolved heavily around big data, its implications ( $\mathrm{Ng} \&$ Wakenshaw, 2016), the opportunities and challenges (Jin et al., 2015) and implementations towards other themes (Hashem et al., 2016). The human keyword was included in this theme, and where humans were discussed as a scope in the Technology theme, it was mostly in terms of usability (Shin, 2017), with less of a focus on policy challenges (Dutton, 2014).

Discussed challenges within the Technology theme were related to data storage, interconnectivity and the complexity of the data. Opportunities that were discussed were; improvements in industry, predictions, addition of artificial intelligence. 
Protection - The protection theme features the keywords Network Security, Security, Data-Privacy and Privacy. It revolves around the security of IoT protocols, threat detection and the aspects of intrusions both in hardware and private data. The following articles have been chosen to highlight the different scopes of the Protection theme:

\begin{tabular}{|l|l|l|c|}
\hline ARTICLE: & AUTHOR(S): & JOURNAL, YEAR: & \#C: \\
\hline $\begin{array}{l}\text { Regulating the internet of things: First } \\
\text { steps toward managing discrimination, } \\
\text { Privacy, Security, And consent }\end{array}$ & Peppet, S.R. & Texas Law Review, 2014 & 75 \\
\hline $\begin{array}{l}\text { Low-energy security: Limits and } \\
\text { opportunities in the internet of things }\end{array}$ & $\begin{array}{l}\text { Trappe, W., Howard, } \\
\text { R., Moore, R.S. }\end{array}$ & $\begin{array}{l}\text { IEEE Security and } \\
\text { Privacy, 2015 }\end{array}$ & 65 \\
\hline $\begin{array}{l}\text { The Internet of Things: a security point } \\
\text { of view }\end{array}$ & $\begin{array}{l}\text { Li, S., Tryfonas, T., Li, } \\
\text { H. }\end{array}$ & Internet Research, 2016 & 56 \\
\hline $\begin{array}{l}\text { Internet of Things: Convenience vs. } \\
\text { privacy and secrecy }\end{array}$ & $\begin{array}{l}\text { Weinberg, B.D., Milne, } \\
\text { G.R., Andonova, Y.G., } \\
\text { Hajjat, F.M. }\end{array}$ & Business Horizons, 2015 & 55 \\
\hline $\begin{array}{l}\text { SecKit: A Model-based Security } \\
\text { Toolkit for the Internet of Things }\end{array}$ & $\begin{array}{l}\text { Neisse, R., Steri, G., } \\
\text { Fovino, I.N., Baldini, G. }\end{array}$ & $\begin{array}{l}\text { Computers and Security, } \\
\text { 2015 }\end{array}$ & 50 \\
\hline
\end{tabular}

Table 6. List of keyword ID, connected article, author(s), journal, year and number of citations for the "Protection" theme.

Analysis of the clusters in VOSviewer showed that in general the Protection theme was relatively disconnected from the other themes, they linked towards other themes, however the strongest connection within the Protection theme was within itself. The keyword privacy was the only word within the cluster connecting to human, with other the strongest connections being within its own cluster. Other connections were towards the Technology, Infrastructure and Logistics themes. The only keyword connecting towards the Organization theme was network security. The strongest link in this theme were between data privacy as well as big data, which is indicative of the literature.

In terms of scope, the Protection theme were less consistent than the other themes. Where most other themes would have a fairly clear delimitation, the protection theme had a wider area of interest, and the scoping was fairly spotty - ranging between the technical and the personal. One of the prominent scopes within this theme dealt with data security - connected to keywords Network Security and Security in terms of networks, hardware and security in an organizational setting (Neisse et al., 2015; Trappe et al., 2015; Li et al., 2016).

The second scope related to personal security in regards to informing, lawmaking, individual privacy and data privacy issues (Peppet, 2014; Weinberg, 2015) - worth noting is that this scope appeared to be somewhat smaller than litterature dealing with technical security issues.

Discussed challenges within the Protection theme were related to encryption, data transfer, the human factor and hacking. Opportunities identified within the Protection theme entails novel security solutions, advances in cryptography. 


\section{Discussion.}

\subsection{Suggestions for a new thematic scope}

Looking at the themes and the scopes within them, it can be argued that they show consistency with each other in terms of the key concepts, and the areas of interest within each one. While this is to be expected, it also highlights the exceptions to these expectations, making eventual outliers stand out in comparison. In this case, three notable exceptions were identified as part of the analysis, the first two being the keywords education and human within the Technology theme, and privacy from the Protection theme.

Within the Technology theme the keywords human and education stood out in comparison to the more consistent tech-oriented keywords - these two keywords were weak in their connection towards the other themes, and one speculation as to why could be that they do not fit particularly well within the Technology theme itself. However, they do not fit particularly well in any of the other themes either.

The same could be said about the keyword privacy within the Protection theme. It was the only keyword from the Protection theme that had a connection towards human, and examined papers with this keyword tended to have a scope closer to human-centric aspects rather than techno-centric aspects. In lacking a clear thematic connection, these three keywords form the weakest connections to the other themes and keywords, where one could expect human to play a larger role within the social science literature.

However low, the occurrence of the keywords still made them relevant, showing that an interest still exists and it could be argued that if the keywords privacy, education and privacy were instead used together more often in connection to other themes, a sixth theme could emerge filling a research gap in terms of the human-centric aspect, which does appear to be lacking. Such keywords as human, education and privacy, could make up the beginning of an Ethics theme - a concept with a scope that this study deems to be understudied within the IoT literature in the social science subject field.

\subsection{Why should the social sciences care}

As described in the introduction of this study, the value of IoT by 2020 is estimated to reach 1.3 trillion dollars, with 30 billion connected devices, and having the potential to change the technological world (Statista, 2019; Ericsson, 2016; Porter\&Heppelmann, 2014). These estimations should get the attention for more than just business opportunities and IoT-driven economic gains.

Social scientists should arguably be at the forefront of this phenomenon, examining the effect of this paradigm shift on the individuals and groups that are exposed to it. In the paper by Lee \& Lee (2015) a study is referenced where only $22 \%$ of the participants felt that the benefits provided by a smart device made up for any privacy issues, and in the paper by Weinberg (2015) privacy was highlighted as an important factor among consumers, and it was expressed as something that managers needed to adhere to in terms of privacy and education. 
The literature selection highlighted an over-representation of IoT-articles outside the subject field of social science - where 14,991 articles were removed, because of the subject fields differing from the ones chosen (See Figure 1). It can be assumed that ethical concerns will most likely not be a primary issue among the engineers and computer scientists working on technical aspects, which is why this paper argue that the social sciences can stand to add value and enrich research through cross-disciplinary co-operation (Wittrock, 2010). Because of the social sciences ongoing involvement in IoT-research, a cross-disciplinary co-operation should not pose any major difficulties and allow for either field to learn from one another and in turn produce higher quality research.

Addressing the concerns surrounding ethical and human-centric aspects can further examine issues and opportunities raised within the five identified themes, for example the engagement of small businesses (Kusiak, 2018), identifying incentives for participation (Salim \& Haque, 2015) or formulating customer relationships (Dijkman et al., 2015). Shifting research, and exploring IoT from a human-centric perspective can contribute towards research, and help facilitate participation, and education towards research and practice, and - if indicative of research from other areas - help with acceptance amongst the users (Gallivan et al., 2005; Botta-Genoulaz \& Millet, 2006).

\section{Conclusions and Suggestions for Future Research.}

This scoping study has aimed at identifying topics of discussions surrounding IoT in social science journals.

The research question asked was: "What areas are being addressed within the social science subject-field of IoT-literature in research journals - and where can further social science research stand to contribute?"

This study have identified 25 commonly occurring keywords, in regards to IoT literature within the social sciences, and divided them into 5 clusters. Keyword clusters were used to formulate five key IoT-themes; Organization, Logistics, Infrastructure, Technology and Protection. Based on the keyword analysis a sixth theme of Ethics was suggested in order to increase focus on human-centric aspects around IoT research.

This study have presented 24 articles from 20 different journals and given an overview in order to guide and inform where the discussions are happening in terms of IoT within the social sciences. In doing this, the study is providing a contribution in terms of thematizing common keyword-clusters allowing for to the identification of key concepts connected to each keyword as well as highlighting where further research can stand to gain. In doing so this study allows for both practitioners and researchers to get an overview of IoT-themes that are prevalent in literature related to the social science subject field and the scopes within them - assisting with future research.

This study also makes the argument that additional value can be created through increased research towards the human-centric side of IoT, and that the subject-field of social science can contribute by offering a deeper discussion into both ethics and policy making surrounding IoT. In doing this, the social sciences has the potential to influence 
the public, inform law- and policy makers, and ensure that the privacy and integrity of individuals are not being breached as we move towards an even more connected future.

Suggestions for future research is to further deepen the analysis through a structured literature review into either some or all of the themes - in order to test the validity of this scoping study and the themes within it. Further, wile this study is focusing on research journals, it should be compared towards a similar analysis of conference proceedings; in order to contrast them against each other and examine whether they differ from one another, and if so, in what aspect.

\section{References}

1. Anthopoulos, L., Janssen, M., \& Weerakkody, V. (2019). A Unified Smart City Model (USCM) for smart city conceptualization and benchmarking. In Smart Cities and Smart Spaces: Concepts, Methodologies, Tools, and Applications (pp. 247-264). IGI Global.

2. Arksey, H., \& O'Malley, L. (2005). Scoping studies: towards a methodological framework. International journal of social research methodology, 8(1), 19-32.

3. Baldini, G., Botterman, M., Neisse, R., \& Tallacchini, M. (2018). Ethical design in the internet of things. Science and engineering ethics, 1-21.

4. Botta-Genoulaz, V., \& Millet, P. A. (2006). An investigation into the use of ERP systems in the service sector. International journal of production economics, 99(1-2), 202-221.

5. Centre for Science and Technology Studies, Leiden University, "VOSviewer - Visualizing scientific landscapes", VOSviewer, 2018. http://www.vosviewer.com// (Accessed 2019-06-10)

6. Dijkman, R. M., Sprenkels, B., Peeters, T., \& Janssen, A. (2015). Business models for the Internet of Things. International Journal of Information Management, 35(6), 672-678.

7. Elsevier, The largest database of peer-reviewed literature - Scopus | Elsevier Solutions. (2019). https://www.elsevier.com/solutions/scopus (Accessed 2019-06-20)

8. Ericsson. (2016). Cellular Networks for Massive IoT, Enabling Low Power Wide Area Applications. Ericsson White Paper (Uen 284 23-3278). 2016-01. https://www.ericsson.com/assets/local/publications/white-papers/wp_iot.pdf (Accessed 2019-06-25)

9. Gallivan, M. J., Spitler, V. K., \& Koufaris, M. (2005). Does information technology training really matter? A social information processing analysis of coworkers' influence on IT usage in the workplace. Journal of Management Information Systems, 22(1), 153-192.

10. Gretzel, U., Sigala, M., Xiang, Z., \& Koo, C. (2015). Smart tourism: foundations and developments. Electronic Markets, 25(3), 179-188.

11. Grewal, D., Roggeveen, A. L., \& Nordfält, J. (2017). The future of retailing. Journal of Retailing, 93(1), 1-6.

12. Harris, I., Wang, Y., \& Wang, H. (2015). ICT in multimodal transport and technological trends: Unleashing potential for the future. International Journal of Production Economics, 159, 88-103.

13. Hashem, I. A. T., Chang, V., Anuar, N. B., Adewole, K., Yaqoob, I., Gani, A., ... \& Chiroma, H. (2016). The role of big data in smart city. International Journal of Information Management, 36(5), 748-758.

14. H. Dutton, W. (2014). Putting things to work: social and policy challenges for the Internet of things. info, 16(3), 1-21

15. Jin, X., Wah, B. W., Cheng, X., \& Wang, Y. (2015). Significance and challenges of big data research. Big Data Research, 2(2), 59-64. 
16. Kang, H. S., Lee, J. Y., Choi, S., Kim, H., Park, J. H., Son, J. Y., ... \& Do Noh, S. (2016). Smart manufacturing: Past research, present findings, and future directions. International Journal of Precision Engineering and Manufacturing-Green Technology, 3(1), 111-128.

17. Kiel, D., Müller, J. M., Arnold, C., \& Voigt, K. I. (2017). Sustainable industrial value creation: Benefits and challenges of industry 4.0. International Journal of Innovation Management, 21(08), 1740015.

18. Kusiak, A. (2018). Smart manufacturing. International Journal of Production Research, 56(1-2), 508-517.

19. Lee, I., \& Lee, K. (2015). The Internet of Things (IoT): Applications, investments, and challenges for enterprises. Business Horizons, 58(4), 431-440.

20. Lilis, G., Conus, G., Asadi, N., \& Kayal, M. (2017). Towards the next generation of intelligent building: An assessment study of current automation and future IoT based systems with a proposal for transitional design. Sustainable cities and society, 28, 473-481.

21. Neisse, R., Steri, G., Fovino, I. N., \& Baldini, G. (2015). SecKit: a model-based security toolkit for the internet of things. computers \& security, 54, 60-76.

22. Ng, I. C., \& Wakenshaw, S. Y. (2017). The Internet-of-Things: Review and research directions. International Journal of Research in Marketing, 34(1), 3-21.

23. Peppet, S. R. (2014). Regulating the internet of things: first steps toward managing discrimination, privacy, security and consent. Tex. L. Rev., 93, 85.

24. Porter, M. E., \& Heppelmann, J. E. (2014). How smart, connected products are transforming competition. Harvard business review, 92(11), 64-88.

25. Reaidy, P. J., Gunasekaran, A., \& Spalanzani, A. (2015). Bottom-up approach based on Internet of Things for order fulfillment in a collaborative warehousing environment. International Journal of Production Economics, 159, 29-40.

26. Roblek, V., Meško, M., \& Krapež, A. (2016). A complex view of industry 4.0. Sage Open, 6(2), 2158244016653987.

27. Salim, F., \& Haque, U. (2015). Urban computing in the wild: A survey on large scale participation and citizen engagement with ubiquitous computing, cyber physical systems, and Internet of Things. International Journal of Human-Computer Studies, 81, 31-48.

28. Senn, J. (1998). The challenge of relating IS research to practice. Information Resources Management Journal (IRMJ), 11(1), 23-28.

29. Shin, D. H. (2017). Conceptualizing and measuring quality of experience of the internet of things: Exploring how quality is perceived by users. Information \& Management, 54(8), 998-1011.

30. Statista, IoT: Number of connected devices worldwide 2012-2025. (2019). https://www.statista.com/statistics/471264/iot-number-of-connected-devices-worldwide/ (Accessed 2019-0630)

31. Tarschys, D., Lachapelle, G. 2010 Social scientists in the corridors of power, Chapter 8 In ISSC, IDS and UNESCO (2010), World Social Science Report 2010, Knowledge Divides UNESCO Publishing, Paris.

32. Trappe, W., Howard, R., \& Moore, R. S. (2015). Low-energy security: Limits and opportunities in the internet of things. IEEE Security \& Privacy, 13(1), 14-21.

33. Weinberg, B. D., Milne, G. R., Andonova, Y. G., \& Hajjat, F. M. (2015). Internet of Things: Convenience vs. privacy and secrecy. Business Horizons, 58(6), 615-624.

34. Wittrock, B. 2010 Shifting involvements: rethinking the social, the human and the natural, Chapter 6 In ISSC, IDS and UNESCO (2010), World Social Science Report 2010, Knowledge Divides UNESCO Publishing, Paris.

35. Xu, L. D., Xu, E. L., \& Li, L. (2018). Industry 4.0: state of the art and future trends. International Journal of Production Research, 56(8), 294 